\title{
K-Band Cross-Aperture Coupled Circularly Polarized Dual Frequency Microstrip Patch Antenna with Single Feed
}

\author{
Miguel A. Barbosa Kortright \\ University of Puerto Rico, Mayagüez Campus \\ Mayagüez, PR 00680 \\ Miguel.barbosal@upr.edu
}

\author{
Rainee N. Simons \\ NASA Glenn Research Center \\ 21000 Brookpark Road \\ Cleveland, OH 44135 \\ Rainee.N.Simons@nasa.gov
}

\begin{abstract}
The paper presents the design, modeling, simulation, and characterization of a K-band cross-aperture coupled CP microstrip patch antenna element with a single feed for dual frequency operation. The patch element can be used as a building block for a larger planar array for SATCOM.
\end{abstract}

Keywords-cross-aperture; patch; K-band; dual frequency;

\section{INTRODUCTION}

In the past, several authors have investigated cross-aperture coupled circularly polarized (CP) microstrip patch antennas. In [1] a nearly square patch excited by a cross-aperture to produce $\mathrm{CP}$ radiation at $2.45 \mathrm{GHz}$ is reported. The cross-aperture had identical slot lengths and widths and was excited diagonally by a microstrip feed line. In addition, the authors have reported the development of a cavity model to accurately predict the performance of their antenna [2], and furthermore, reported the performance of a $2 \times 2$ sequentially rotated $\mathrm{CP}$ antenna array with a series feed at $5.8 \mathrm{GHz}$ [3]. A few variants of the above basic design have also been reported in the literature for genrating CP. For example, cross slots of unequal lengths etched on a circular patch, which is proximity-coupled to a microstrip feed line is reported at $1.55 \mathrm{GHz}$ [4]. In [5] a nearly square patch, which is aperture coupled through an inclined aperture with endloading V-shaped slots that are perpendicular to each other and are also parallel to the patch edges is reported. The antenna produced $\mathrm{CP}$ radiation at $2.232 \mathrm{GHz}$. In [6] quarter-wavelength section of microstrip feed lines at $2.4 \mathrm{GHz}$ are positioned and connected serially between each arm of a cross-aperture. This arrangement generated the $90^{\circ}$ phase difference required for exciting sequentially rotated surface currents on a square patch. All of the above antenna configurations were intended for operation at a single design frequency.

In this paper, a $\mathrm{CP}$ almost square microstrip patch antenna with corners truncated, and excited by a cross-aperture with unequal slot lengths, for dual frequency SATCOM applications at $\mathrm{K}$-band is reported.

\section{Antenna ELEMENT DESIGN}

\section{A. Cross-Aperture Feed Design}

The feed consists of a cross-aperture with unequal slot length, which is electromagnetically coupled along the diagonal to a $50 \Omega$ microstrip feed line. A high permittivity substrate material was selected to enhance the coupling efficiency. By having unequal slot lengths dual resonance can be achieved as shown later in Section III. The feed and the patch are synergistically modeled, simulated, and optimized using the built-in Trust Region Algorithum in CST Microwave studio 2014. Fig. 1(a) shows the optimized geometry of the feed. Rogers Corporation RT/duroid $6010.2\left(\mathrm{~h}_{\mathrm{f}}=10\right.$ mils, $\left.\varepsilon_{\mathrm{rf}}=10.2\right)$ with $0.5 \mathrm{oz}$ copper cladding $(\mathrm{t}=17 \mu \mathrm{m})$ was used in the design, modeling, and fabrication.

\section{B. Patch Radiator Design}

The patch is an almost square patch with corners truncated for CP. A low permittivity substrate material was chosen to enhance the radiation efficiency. Fig. 1(b) shows the optimized geometry of the patch. Rogers Corporation RT/duroid $5880\left(\mathrm{~h}_{\mathrm{p}}\right.$ $=10$ mils, $\left.\varepsilon_{\mathrm{rp}}=2.2\right)$ with $0.5 \mathrm{oz}$ copper cladding $(\mathrm{t}=17 \mu \mathrm{m})$ was used.

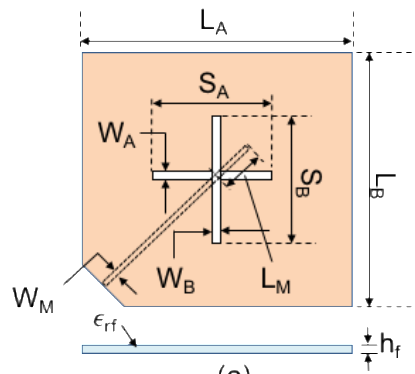

(a)

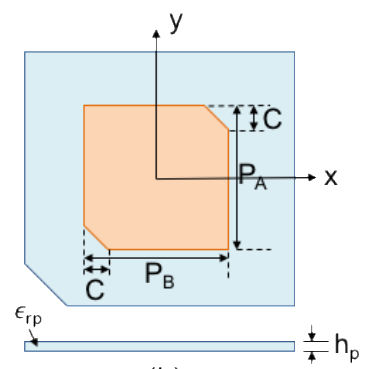

(b)
Fig. 1. (a) Feed substrate with the cross-aperture and diagonal microstrip feed line. (b) Almost square patch with corners truncated for CP. Where all dimensions are in $\mathrm{mm}$ and $\mathrm{L}_{\mathrm{A}}=\mathrm{L}_{\mathrm{B}}=76.2, \mathrm{~S}_{\mathrm{A}}=1.69, \mathrm{~S}_{\mathrm{B}}=1.98, \mathrm{~W}_{\mathrm{A}}=\mathrm{W}_{\mathrm{B}}=$ $0.127, \mathrm{~L}_{\mathrm{M}}=2.84, \mathrm{~W}_{\mathrm{M}}=0.254, \mathrm{P}_{\mathrm{A}}=4.97, \mathrm{P}_{\mathrm{B}}=5.08, \mathrm{C}=0.56$.

\section{ANTENNA ELEMENT CHARACTERIZATION}

The measured return loss of the patch radiator excited by a cross-aperture feed is presented in Fig. 2. The results indicates that the antenna element has good return loss $(<-10.0 \mathrm{~dB})$ over a wide band of frequencies extending from 18.35 to $20.18 \mathrm{GHz}$. At the dual resonance frequencies of $18.5 \mathrm{GHz}$ and $19.5 \mathrm{GHz}$ the return loss is on the order of $-20.0 \mathrm{~dB}$ or better. The simulated radiation patterns at the dual resonance frequencies are presented in Figs. 3 and 4, respectively. The antenna element has good radition patterns in both the principal planes. The 
measured axial ratio of the antenna element over a band of frequencies in the neighbourhood of the dual resonance frequencies is presented in Figs. 5 and 6, respectively. The axial ratio is better than $3 \mathrm{~dB}$ across the frequency range of 18.0 to $18.55 \mathrm{GHz}$ and 19.81 to $20.25 \mathrm{GHz}$. These frequency ranges are next superimposed as a green bar on the return loss characteristics presented in Fig. 2. Clearly, one notices that it is possible to simultaneously obtain good return loss and axial ratio characteristics, which are essential for dual frequency operation.

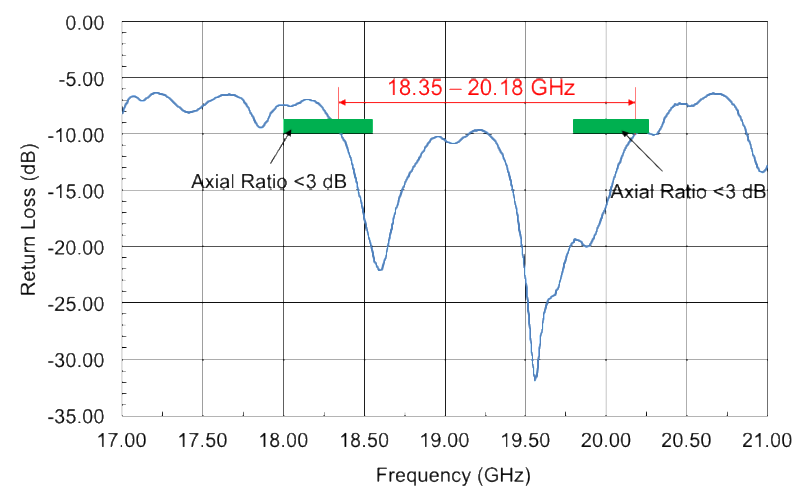

Fig. 2. Measured return loss of the K-band cross-aperture coupled almost square patch with corners truncated.

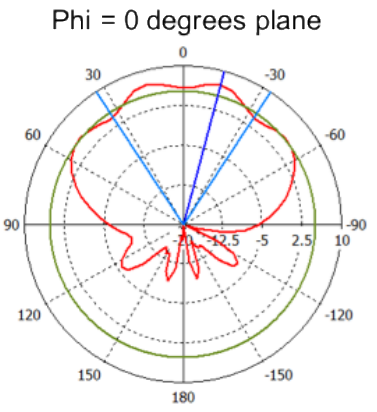

Theta / Degree vs. dBi
Phi $=90$ degrees plane

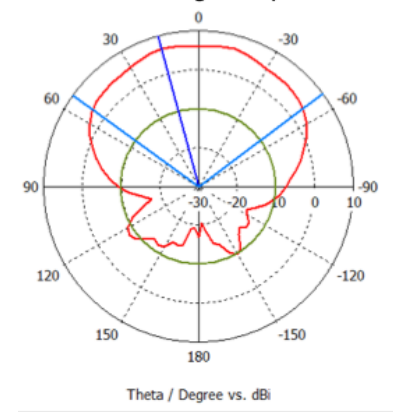

Fig. 3. Simulated radiation patterns at $18.5 \mathrm{GHz}$.

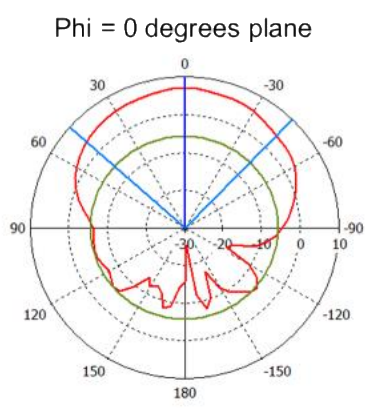

Theta / Degree vs. dBi
Phi $=90$ degrees plane

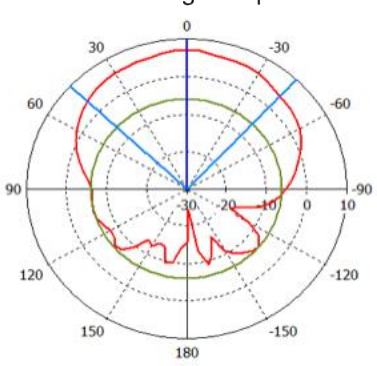

Theta / Degree vs. dBi
Fig. 4. Simulated radiation patterns at $19.5 \mathrm{GHz}$.

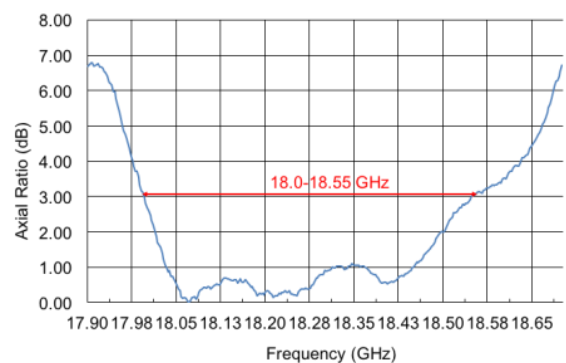

Fig. 5 Measured axial ratio in the 18.0 to $18.55 \mathrm{GHz}$ frequency range.

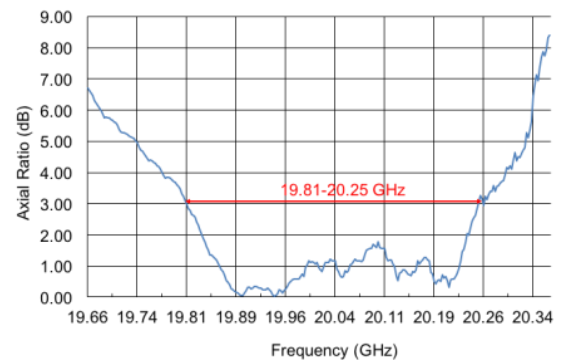

Fig. 6 Measured axial ratio in the 19.81 to $20.25 \mathrm{GHz}$ frequency range

\section{CONCLUSION}

The design, simulation, fabrication, and characterization of a K-band cross-aperture coupled $\mathrm{CP}$ dual frequency microstrip patch antenna with a single feed is presented. The measured results shows that the antenna has good simultaneous return loss and axial ratio performance at dual frequencies. Additionally, the simulated results indicates that the antenna has good radiation patterns at dual frequencies. All of the above was possible because two different set of substrates parameters were used for the feed and the radiator, which allowed the design to be optimized. Lastly, the use of a single feed for dual frequency operation greatly simplifies the array feed network design.

\section{ACKNOWLEDGMENT}

Miguel A. Barbosa Kortright acknowledges NASA Glenn for the 2017 spring, summer, and fall internship opportunities.

\section{REFERENCES}

[1] T. Vlasits, et al., "Performance of a cross-aperture coupled single feed circularly polarized patch antenna," Electronics Letters, vol. 32, no. 7, pp. 612-613, March 1996.

[2] B.Al-Jibouri, et al., "Cavity model of circularly polarized cross-aperturecoupled microstrip antenna," IEE Proc. Microwaves, Antennas and Propagation, vol. 148, no. 3, pp. 147- 152, June 2001.

[3] H. Evans and A. Sambell, "Wideband $2 \times 2$ sequentially rotated patch antenna array with series feed," Microwave and Optical Technology Letters, vol. 40, no. 4, pp. 292-294, Feb 2004.

[4] H. Iwasaki, "A circularly polarized small-size microstrip antenna with a cross slot," IEEE Trans Antennas and Propagation, vol. 44, no. 10, pp. 1399-1401, Oct 1996.

[5] C.-Y. Huang, et al., "Slot-coupled microstrip antenna for broadband circular polarization," Electronics letters, vol. 34, no. 9, pp. 835-836, April 1998.

[6] H. Kim, et al., "A single-feeding circularly polarized microstrip antenna with the effect of hybrid feeding," IEEE Antennas and Wireless Propagation Letters, vol. 2, pp. 74-77, 2003. 